\title{
RESULTS AT GERDAU MONROE USING TALLMAN SUPERSONIC CARBON INJECTION SYSTEM *
}

\author{
Steven Gillgrass ${ }^{1}$ \\ Michael Strelbisky² \\ Rafael Bruch ${ }^{3}$ \\ Ernesto Rheinboldt $t^{4}$
}

\begin{abstract}
Gerdau Monroe has installed and commissioned the Tallman Supersonic Carbon Injection system (TSCi ${ }^{\mathrm{TM}}$ ) for use in their 135-ton Electric Arc Furnace (EAF) located in Monroe, MI. TSCi ${ }^{\mathrm{TM}}$ is an innovative injection system with the primary aim of improving injection carbon delivery to the steel bath by increasing efficiency. It is proven technology with installations at numerous steelmaking facilities all over the world. Results from installation and commissioning of $\mathrm{TSC} \mathrm{i}^{\mathrm{TM}}$ at Gerdau Monroe will be reported as well as on-going trials and optimization efforts. Standard injection systems deliver carbonaceous material from a vessel to the EAF using air where it is injected through a lance pipe or oxy-fuel burner. Using this method, material delivery to the EAF is limited by the pressure and velocity of the transport air. Loss of efficiency can be observed by looking at the quality of the injection carbon stream during operation or by measuring loss on ignition of EAF slag or off-gas system dust. TSCiTM uses a patented design and proprietary technology to improve delivery of carbonaceous material to the EAF. Using this method, savings at Gerdau Monroe were realized by reducing the amount of carbon used in each heat while maintaining or improving upon existing foamy slag practice. As well, significant savings were achieved as a result of reduced $\mathrm{FeO}$ content in the slag and improved recovery of iron. Additional savings can be realized by using a smaller mesh material to take advantage of lower material cost and higher injected surface area. Other inherent benefits to improved injection carbon include lower energy and electrode consumption, reduced refractory wear and reduced maintenance cost.
\end{abstract}

Keywords: Carbon Injection; Foamy Slag; Electric Arc Furnace; EAF

Senior Application Engineer, A.H. Tallman Bronze Company Ltd., Canada

President, A.H. Tallman Bronze Company Ltd., Canada

Meltshop Process Engineer, Gerdau Special Steel North America - Monroe, USA

Technical Sales Representative, A.H. Tallman Bronze Company Ltd., Brazil. 


\section{INTRODUCTION}

Gerdau Monroe has installed and commissioned the Tallman Supersonic Carbon Injection system (TSCi ${ }^{\mathrm{TM}}$ ) for use in their 135-ton Electric Arc Furnace (EAF) located in Monroe, MI. TSCim is an innovative injection system with the primary aim of improving injection carbon delivery to the steel bath by increasing efficiency. It is proven technology with installations at numerous steelmaking facilities all over the world. Results from installation and commissioning of $\mathrm{TSCi}^{\mathrm{TM}}$ at Gerdau Monroe will be reported as well as on-going trials and optimization efforts.

Standard injection systems deliver carbonaceous material from a vessel to the EAF using air where it is injected through a lance pipe or oxy-fuel burner. Using this method, material delivery to the EAF is limited by the pressure and velocity of the transport air. Loss of efficiency can be observed by looking at the quality of the injection carbon stream during operation or by measuring loss on ignition of EAF slag or off-gas system dust.

$\mathrm{TSCi}^{\mathrm{TM}}$ uses a patented design and proprietary technology to improve delivery of carbonaceous material to the EAF. Using this method, savings at Gerdau Monroe were realized by reducing the amount of carbon used in each heat while maintaining or improving upon existing foamy slag practice. As well, significant savings were achieved as a result of reduced $\mathrm{FeO}$ content in the slag and improved recovery of iron. Additional savings can be realized by using a smaller mesh material to take advantage of lower material cost and higher injected surface area. Other inherent benefits to improved injection carbon include lower energy and electrode consumption, reduced refractory wear and reduced maintenance cost.

\section{DISCUSSION}

\section{Current Operations}

The majority of Electric Arc Furnace operations inject carbonaceous material using 'Dense Phase' conveying. Material transported by this method is stored in a pressure vessel and compressed air forces it into the conveying line for delivery to the EAF. Supplementary air injectors can be added along the conveying line to maintain conveying velocity, overcome resistance from long distances and minimize line plugging. This method for conveying carbonaceous material is characterized by high pressure and low velocity.

Once at the EAF, material is injected through pipes and/or oxy-fuel burners. Regardless of design, these methods utilize a straight pipe design and material delivery to the EAF is accomplished by 'pushing' the carbon material through the system, down the straight-walled pipe and into the EAF. Thus, delivery of material is limited by the pressure difference between the injection system and the EAF atmosphere as well as the velocity of the transport air.

As a result, efficiency of delivery of carbonaceous material is reduced. There is insufficient pressure to overcome the EAF atmosphere and insufficient velocity for material to be delivered efficiently to the slag or slag-metal interface. By this method, injected material (particularly smaller particle sizes) is lost to the fume system or combusted in the freeboard and material that does reach the slag tends to sit on top. 
Increasing the air pressure in the line will not improve the situation greatly as it will result in increased wear of supply hoses, increased demand of air from compressors, and little change in the pressure difference or velocity of the material entering the EAF.

"Dilute Phase" conveying can also be used where material transported by this method is fed into an air stream created by a blower fan. Particles are trapped in the air stream for delivery to the EAF. This method for conveying is characterized by low pressure and high velocityii. Higher velocity of the injected carbon improves delivery to the slag but lower pressure than 'Dense Phase' conveying still results in loss of efficiency due to material being lost to the fume system or combusted in the freeboard. Additionally, 'Dilute Phase' conveying over long distances typically seen in steelmaking operations, particularly where multiple points of injection are required, would generally result in high maintenance requirements on conveying pipe, fittings and elbows due to higher velocities and increased potential for abrasion.

Figure 1 shows a typical example of carbonaceous material being injected into an EAF. It can be seen that as the material is injected, the shape of the stream increases in size as a result of the pressure difference between the conveying stream and the EAF atmosphere. Under these circumstances, material delivery efficiency is lost as there is insufficient 'push' to deliver carbon to the slag or slag-metal interface to initiate foaming. In most cases, finer carbon particles are combusted in the freeboard or simply lost to the fume system. The exiting material is travelling at subsonic speeds, which quickly spreads into a cloud.

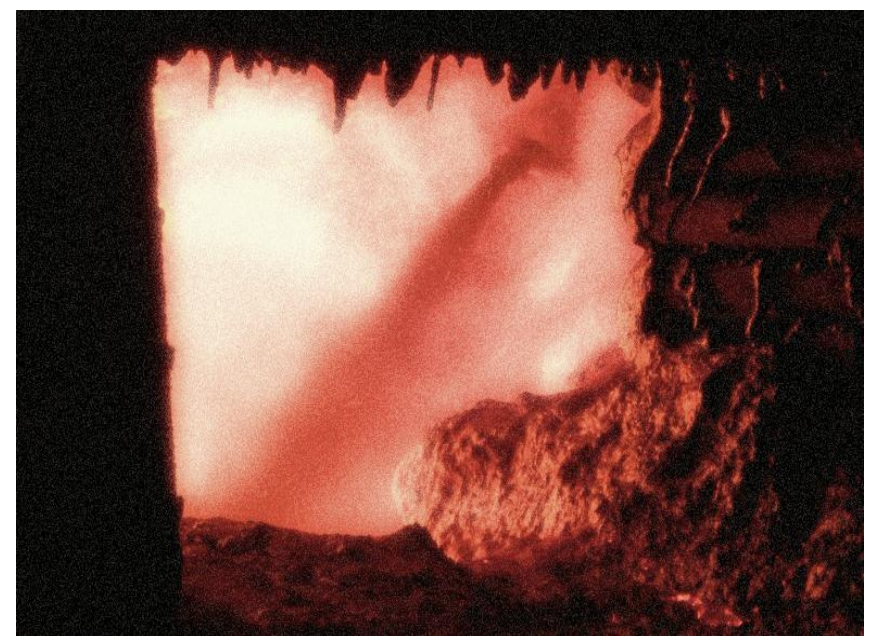

Figure 1. Injection of Carbonaceous Material into EAF using Straight Pipe Method.

\section{Tallman Supersonic Carbon Injector (TSC $i^{\mathrm{TM}}$ )}

TSCi ${ }^{\mathrm{TM}}$ uses a patented design and proprietary technology to improve delivery of carbonaceous material to the EAF. The TSCi ${ }^{\mathrm{TM}}$ has three (3) primary inputs. Carbon is supplied to the unit via the "Carbon-In" port; the existing supply hose is attached to this port. Inert gas (typically air or nitrogen) is supplied to 2 input connections, "Shroud Air" port and "Transport Air" port. These can be separate lines to the air supply, or a T connection can be used to split a single air source and feed it to both air connections on the $\mathrm{TSCi}^{\mathrm{TM}}$ through pressure regulators. (See Figure 2). 


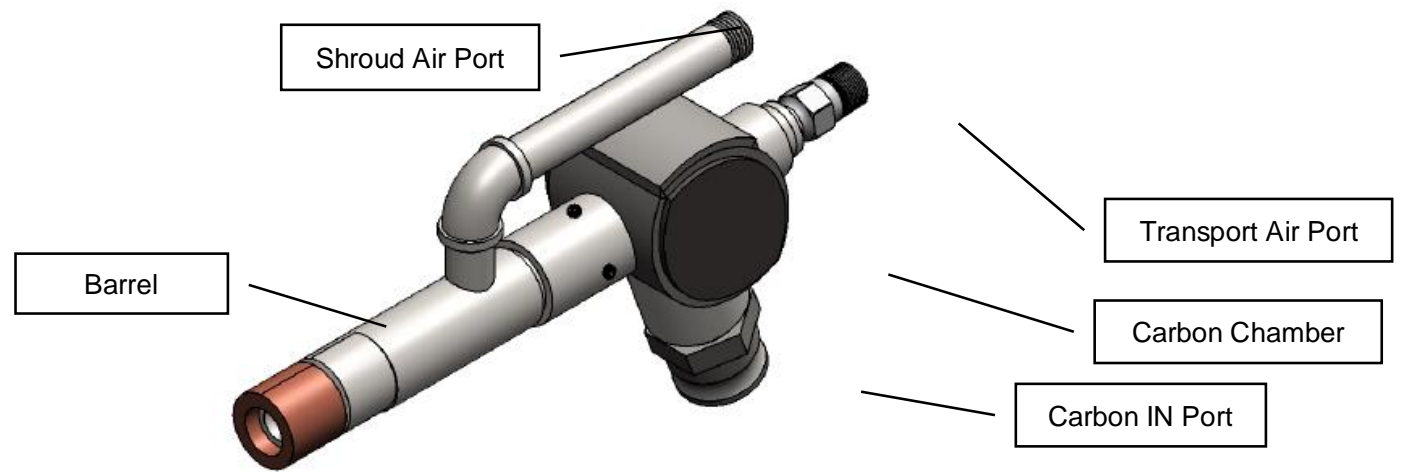

Figure 2. $\mathrm{TSCi}^{\mathrm{TM}}$ - Operational Schematic.

Supply air travels through a designed de Laval nozzle, creating a supersonic jet with approximately $\mathrm{MACH} 2$ value. While the supplied injection carbon is being pushed by pressure from the holding tank, the supersonic jet creates a venturi effect and the resultant negative pressure draws injection carbon into the Carbon Chamber.

The injection carbon entering the Carbon Chamber enters into the supersonic jet path and is accelerated down the Barrel. Injection carbon travels through the central pipe and upon exiting the pipe is shrouded by an annular supersonic jet created by air from the Shroud Air Port. The annular supersonic jet prevents the spread of injection carbon from the stream. Figure 3 shows a comparison between an existing injection system and the $\mathrm{TSCi}^{\mathrm{TM}}$. It can be seen that the injected material travels a much greater distance with little degradation of the stream.
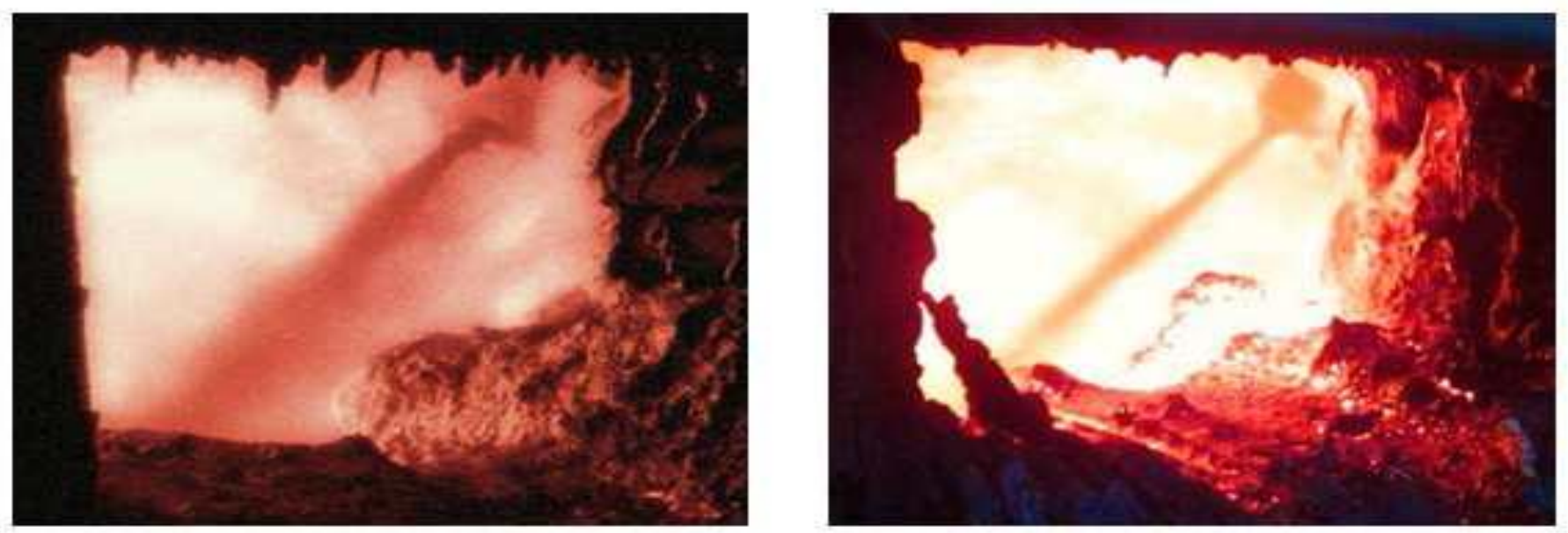

Figure 3. Straight Pipe Carbon Injector (Left) versus TSCI ${ }^{\mathrm{TM}}$.

\section{Installation at Gerdau Monroe}

One (1) TSCi ${ }^{\mathrm{TM}}$ was installed at Gerdau Monroe in January 2016. A second injector was installed in April 2016. Details of the installation can be seen in Figure 4. 


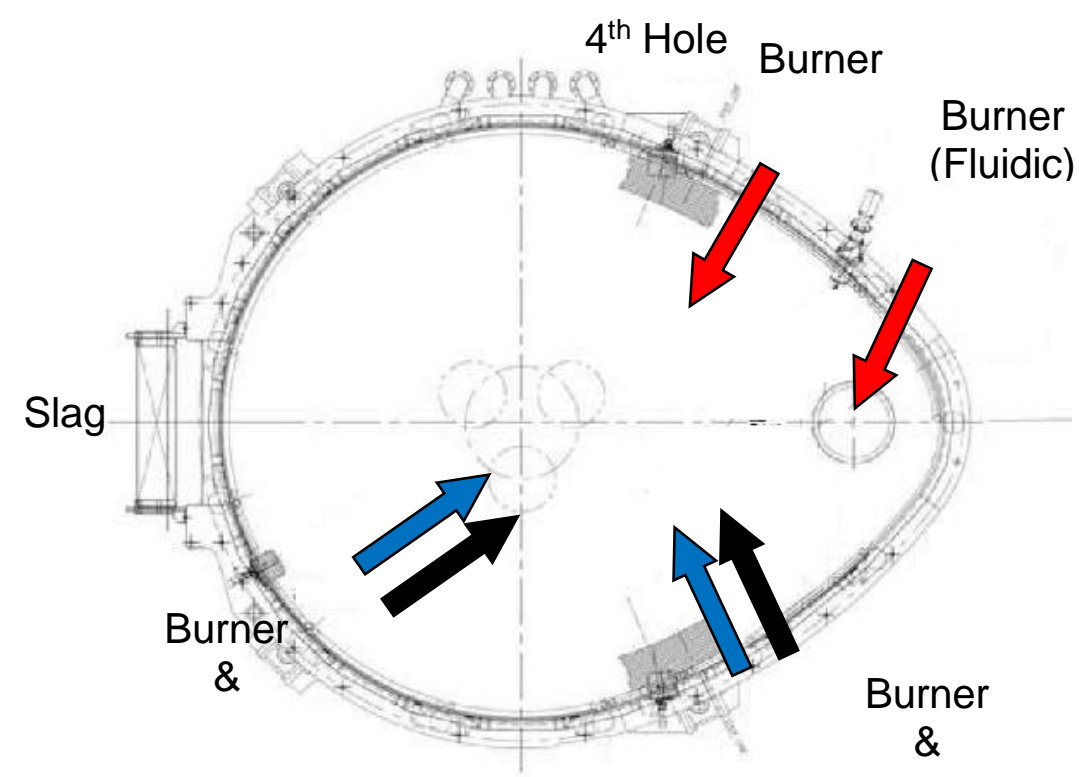

Figure 4. Top view of EAF at Gerdau Monroe.

For injection carbon material, Gerdau Monroe has used Metallurgical Coke, Anthracite and Petroleum Coke depending on cost and uses the finest sizes available (Metallurgical Coke = Breeze (1/4" x 0"), Anthracite = Buckwheat \#5 (3/64" $x$ 0"), Petroleum Coke $=10$ Mesh $(2 \mathrm{~mm} \times 0)$ ). The finest size of injection carbon material is preferred as foamy slag formation is directly proportional to higher surface area of carbon particles.

Results from Gerdau Monroe for total carbon consumption are shown in Figure 5. From February to May 2016, we see a decrease in injection carbon consumption of approximately $20 \%$ from the established baseline and a decrease in charge carbon consumption of approximately $32 \%$ from the established baseline. During this period, a second injector was installed (April 2016).

Following the installation of the second $\mathrm{TSCi}^{\mathrm{TM}}$, a process change initiative was taken at Gerdau Monroe to significantly reduce or eliminate charge carbon usage. This initiative was taken due to poor recovery of charge carbon and higher efficiency of injected carbon. From June 2016 to December 2016, we see an increase in injection carbon consumption of approximately $18 \%$ from the established baseline and a decrease in charge carbon of approximately $85 \%$ from the established baseline. 


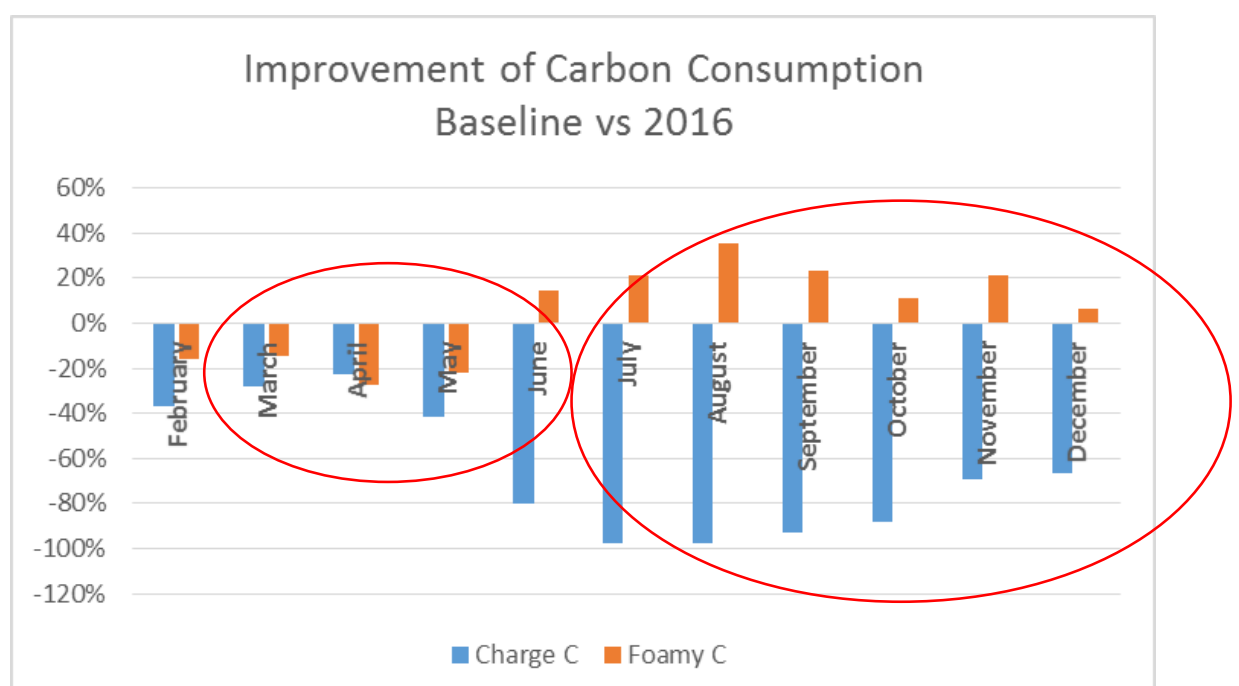

Figure 5. Carbon Consumption at Gerdau Monroe vs. Established Baseline.

Figure 6 shows $\mathrm{FeO}$ content in the slag at Gerdau Monroe compared to the established baseline. It can be seen that during the time of operation of $\mathrm{TSCi}^{\mathrm{TM}}$ at Gerdau Monroe, there has been a decrease of $3.0 \%$ in $\mathrm{FeO}$ content.

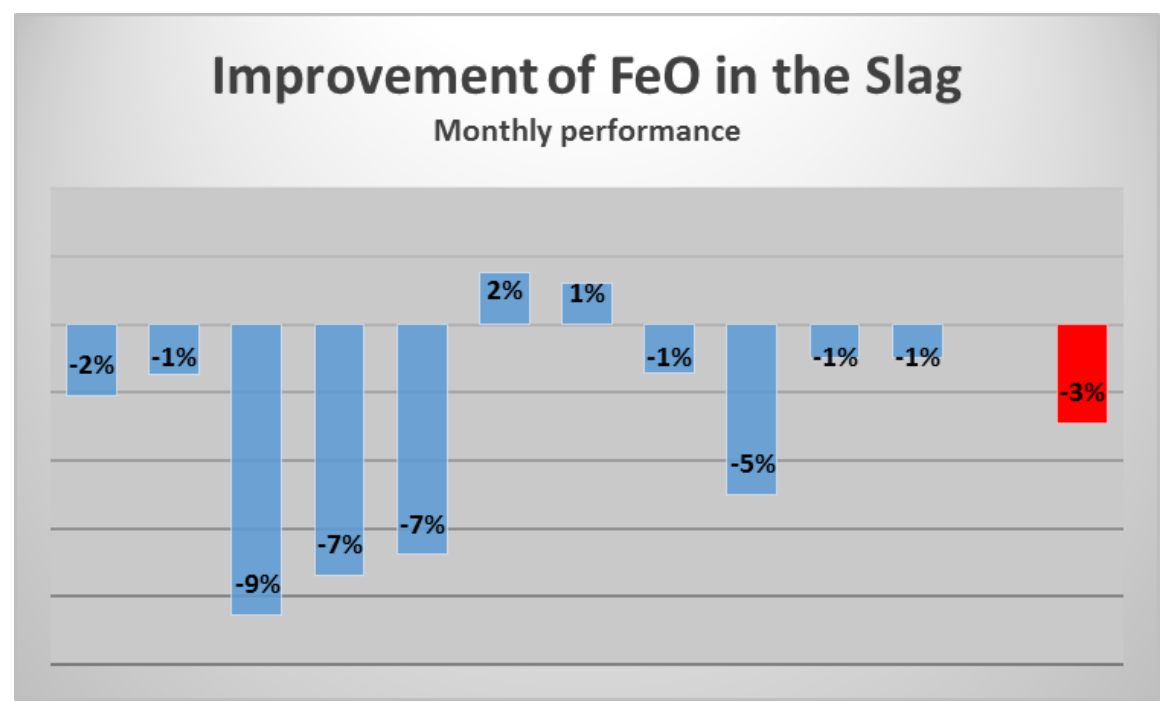

Figure 6. FeO Content in EAF Slag at Gerdau Monroe vs. Established Baseline.

While the entirety of these improvements cannot be definitively attributed to $\mathrm{TSCi} \mathrm{T}^{\mathrm{TM}}$ and improved efficiency of injection carbon, with $\mathrm{TSCi}^{\mathrm{TM}}$, it was possible to efficiently deliver injection carbon to the slag and slag-metal interface, reducing losses and allowing for a reduction in the total carbon consumption in the EAF. In fundamental terms, the rate of decarburization in the EAF can be described by the following equation:

$$
\frac{d \% C}{d t}=\frac{m_{C} *\left(\% C_{B a t h}-\% C_{e q}\right)}{h}
$$

Equation 1. Rate of Change in $\%$ Carbon with Time ${ }^{\text {iii }}$

Where, $\mathrm{mc}_{\mathrm{c}}$ is the mass transfer coefficient and $\mathrm{h}$ is the depth of the bath. The rate of decarburization is proportional to the difference of the bath carbon $\% \mathrm{C}_{\text {bath }}$ and the 
equilibrium carbon $\% \mathrm{C}_{e q}$ as determined by the oxygen activity where $\mathrm{mc}_{\mathrm{c}} \mathrm{h}$ and oxygen activity are all dependent on the specific EAF. Pretorius et al. simulated the principle of decarburization in the EAF which serves to describe the reduction in carbon consumption and FeO content seen at Gerdau Monroe.

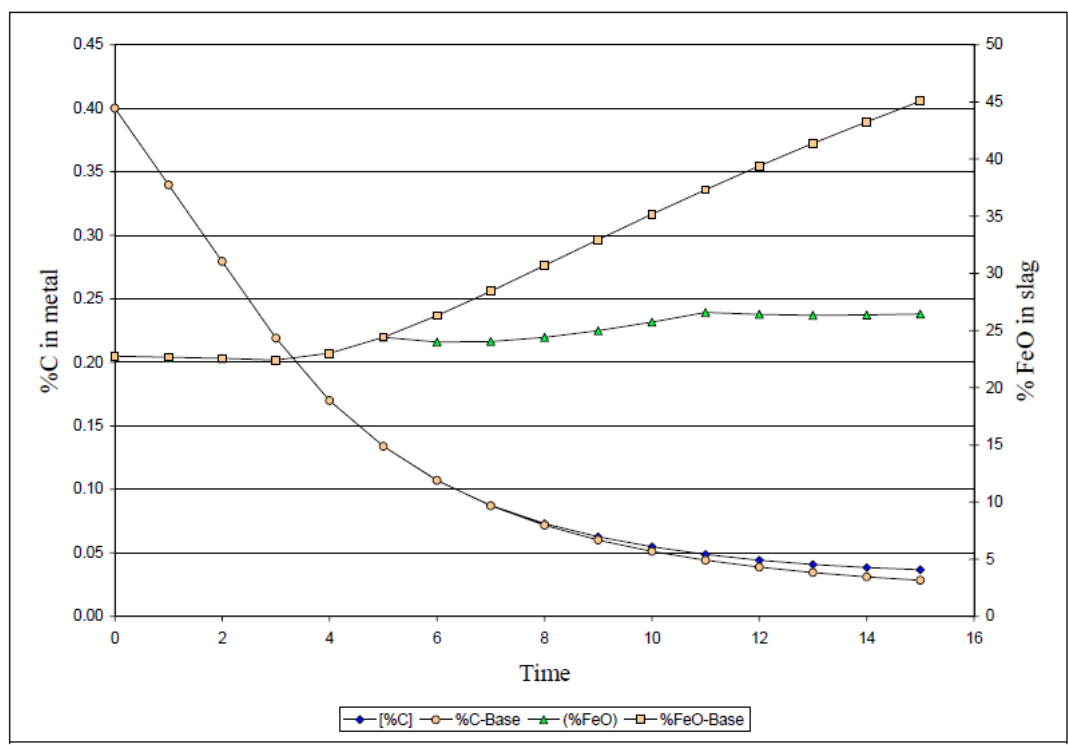

Figure 7. Simulation of EAF refining periodiv

As refining time increases, the decarburization mechanism becomes dependent on mass transfer (or diffusion) of carbon to areas where oxygen can initiate a reaction. In this case, the amount of oxygen injected to the bath will only serve to oxidize iron, increasing $\mathrm{FeO}$ content in the slag with little decarburization benefit. Increasing carbon content in the bath (and slag) becomes the only way to effectively generate carbon monoxide for slag foaming and $\mathrm{FeO}$ reduction. As charge carbon is used to attempt to increase the carbon content in the bath but has dramatically variable efficiency, it is clear that injecting carbon to the slag-metal interface is preferable to charge carbon use in influencing the carbon content in the bath (and slag).

Direct benefits such as reduction of carbon consumption and FeO content are not the only benefits with improved carbon injection efficiency. Figure 8 shows Electrical Energy Consumption at Gerdau Monroe compared to the established baseline. 


\section{Improvement of Electric Energy Consumption}

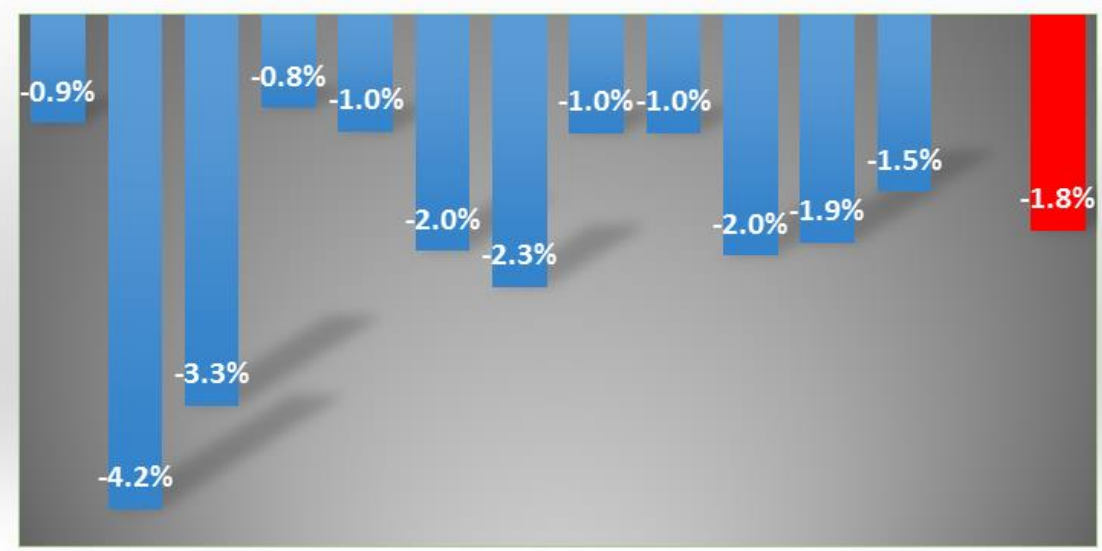

Figure 8. Electrical Energy Consumption at Gerdau Monroe vs Established Baseline.

It can be seen that during the time of operation of $\mathrm{TSCi}^{\mathrm{TM}}$ at Gerdau Monroe, there has been a decrease of $1.8 \%$ in electrical energy consumption. While the entirety of this improvement cannot be attributed to improved efficiency of injection carbon, the results can also be seen in improved arc stability, particularly during times when foamy slag is critical (flat bath). The benefits of foamy slag practice in Electric Arc Furnace steelmaking are well documented. Figure 9 shows these benefits $^{v}$. It is critical to the steelmaker to have good foamy slag practice and efficient delivery of injection carbon to the slag only serves to improve the practice.
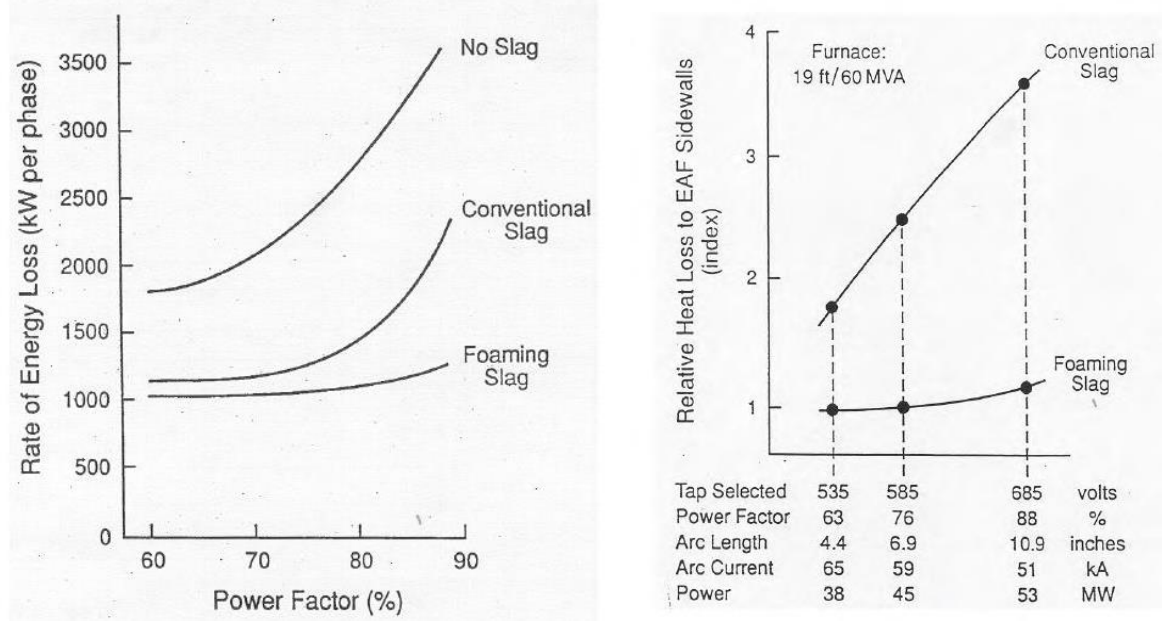

Figure 9. Established Benefits of Foamy Slag on Electrical Energy Consumption in EAF Steelmaking ${ }^{v}$

\section{CONCLUSIONS}

The combination of the central jet and the annular supersonic jet in the $\mathrm{TSCi}^{\mathrm{TM}}$ allows the injection carbon to travel farther into the EAF with increased momentum than standard 'straight pipe' injection. This improves carbon usage efficiency as there is less carbon lost to the off-gas system due to not reaching the slag or slag-metal interface. Initial results at Gerdau Monroe showed a reduction in injection carbon consumption of approximately $20 \%$ along with a reduction in charge carbon of approximately $32 \%$ compared to established baseline. A change in process has led 
to a significant decrease charge carbon consumption with an increase in injection carbon consumption while maintaining gains in electrical energy consumption and reducing $\mathrm{FeO}$ content in the slag.

\section{REFERENCES}

i F. Novelli, "A Quick Look at Pneumatic Convey Systems Basics", Powder \& Bulk Engineering, March 2010

ii F. Novelli, "A Quick Look at Pneumatic Convey Systems Basics”, Powder \& Bulk Engineering, March 2010

iii E. Pretorius, H. Oltmann, and J. Jones, EAF Fundamentals (York, PA: LWB Refractories)

iv E. Pretorius, H. Oltmann, and J. Jones, EAF Fundamentals (York, PA: LWB Refractories)

v The Making, Shaping and Treating of Steel $-11^{\text {th }}$ Edition, AISE Foundation (1998)) 